\title{
Where there's smoke, there's fire
}

\author{
Simon Chapman
}

The scene is familiar to every driver. You're driving along at night and suddenly the driver in front discards a cigarette butt. The sparks startle as the butt glances across the road. It's such a common sight, it barely rates a mention. But every now and then one of these butts settles, still glowing, in roadside debris and starts a fire. Fire authorities have deadpan ledger entries in their annual reports about this. For example, in 1992 there were 1525 fires in the state of New South Wales, Australia caused by discarded smoking materials-including 623 bush and grass fires and 360 fires in buildings.

Coronial and other government inquiries following the depressingly common summer month bush fires in Australia present an unprecedented opportunity for some serious action on the role of cigarettes in starting fires. In both the community rage, and the more considered thinking that choruses through the marathon radio talkback sessions during and after such fires, cigarettes are frequently discussed. Often this talk focuses on the low-life mentality of those who throw their butts out of car windows.

However, it is tragically myopic when the official reports on the cause and future prevention of bush fires also define the cigarette issue as one of thoughtlessness, only requiring some cheery ditty campaign suggesting smokers "do the right thing" and dispose of butts carefully. As smoking becomes increasingly an antisocial habit, such appeals to civic-mindedness and consideration will be as useless as an ashtray on a motorbike. A thousand polystyrene hamburger cartons tossed out of car windows are merely unsightly. But just one discarded butt that razes tens of thousands of square kilometres, kills stock and wildlife and all too often humans, is a problem deserving different thinking.

House fires too are highly relevant to this issue. Each year a quarter of all fire deaths are caused by cigarettes. Smokers, often intoxicated, fall asleep in bed or on a couch with a lighted cigarette. ${ }^{1}$ Many of the most poignant victims are babies and small children who are unable to escape the infernos that result. ${ }^{2}$

The greatest promise for prevention lies in

Department of Public Health and

Community Medicine, University of Sydney [A27], NSW 2006, Australia

S Chapman

simonc@pub.

health.usyd.edu.au modifying the product, not the smoker, as Andrew McGuire documents in this issue. ${ }^{3}$ The fire-safe cigarette-the cigarette engineered so that its propensity to combustibility is dramatically reduced-is a reality that the tobacco industry knows all about, but which governments refuse to mandate.
In 1987 four American tobacco giants (Philip Morris, RJ Reynolds, American Tobacco and Lorillard) participated in and agreed with the conclusions of a three-year study commissioned by the United States Congress. Following lobbying from burn victims, burn surgeons, nurses and firefighters, President Ronald Reagan had signed the Cigarette Safety Act in October 1984, and in 1987 an eight-volume report was submitted to Congress, following exhaustive experiments in which upholstered furniture and mattresses were subjected to different smouldering cigarettes. The report found that "it is technically feasible and may be commercially feasible to develop cigarettes that will have a significantly reduced propensity to ignite upholstered furniture or mattresses. Furthermore, the overall impact on other aspects of United States society and economy may be minimal. Thus it may be possible to solve this problem at costs that are less than the potential benefits." ${ }^{4}$

The trick lies in the design and chemistry of the cigarettes. The main factors that contribute to the combustibility of cigarettes are the density of the tobacco, the porosity of cigarette paper and a reduction in citrate added to the paper. Two tobacco manufacturers involved in the study, using existing technology, equipment, and raw materials, produced 1000 examples of 41 different prototypes where these variables were each different. The best of the test cigarettes ignited test materials 5-20\% of the time, whereas regular commercial cigarettes caused fires in $90-100 \%$ of the tests.

The Bush administration picked up the baton handed to Congress by the report team but swiftly passed it into "further research" committees at the behest of the powerful southern tobacco lobby. As McGuire explains, it has never seen the legislative light of day.

Australian governments are no strangers to international innovation in controlling the tobacco industry. The South Australian government was one of the first in the world to ban smokeless tobacco in $1986 .^{5}$ In the same year it also was the first in the world to ban small "kiddie" packs of 15 cigarettes, following research that showed how successfully they were being marketed to children. ${ }^{6}$

Australia, with its tinderbox environment, an lost much of its political huff and puff, and a smoking prevalence that has declined about $1-2 \%$ a year over the past 20 years, faces a perfect opportunity to again lead the world in being the first to introduce fire-safe cigarettes. 
With international "domino effects" being legion in the regulation of tobacco products, the lives saved, the disfigurement avoided, and the bushland and property damage spared around the world in generations to come as a result of such a lead would be simply monumental. In 1987, China's worst ever forest fire saw 13000 square kilometres ravaged, 300 people killed and 5000 made homeless. A discarded cigarette was thought to be involved. ${ }^{7}$

Alan Blum once wrote a provocative article entitled "If smoking killed baby seals ...". Blum argued that the public and governments would be more moved to control the tobacco industry if tobacco killed cute animals like baby seals rather than people mostly in middle and later life. In 1997, motorists in New South Wales were confronted with billboards showing the photograph on our front cover. The charred carcass of a kangaroo under the words "Smoking Kills" was a stark reminder of the possible consequences of discarding cigarette butts from vehicles travelling in Australia's vast, dry interior.

The advertisement on the cover of this issue was produced by the Australian National Roads and Motorists Association in 1997 as part of a broader programme of raising motorists' awareness of environmental aspects of motoring. I cannot recall any government public awareness campaign ever warning about the dangers of smoking in bed, on soft furniture, or from discarding glowing butts from cars into roadside debris.

Over five trillion cigarettes are smoked worldwide each year. Countless millions of these are discarded and the same will happen this year, next year, and every year. Governments can shrug this off as unavoidable, or they can legislate to render such mindlessness largely harmless. To fail to do so will inevitably, as Andrew McGuire warns, keep the home and bush fires burning.

1 English DR, Holman CDJ, Milne E, et al. The quantification of drug caused morbidity and mortality in Australia, 1995 ed. Canberra, ACT: Commonwealth Department of Human Services and Health, 1995.

2 Anon. NSW: fire family critical-lit cigarette focus of inquiry. Australian Associated Press, 1997:Oct 20.

McGuire A. How the tobacco industry continues to keep the home fires burning. Tobacco Control 1999;8:67-69.

4 Technical Study Group. Toward a less fire-prone cigarette: final report of the technical study group on cigarette and little cigar fire safety. Bethesda, Maryland: US Consumer Product fire safety. Bethesda, Marylan.

5 Chapman S, Reynolds C. Regulating tobacco-the South Australian Tobacco Products Control Act 1986. Commun Hustralian Tobacco Products Contro

6 Wilson DH, Wakefield MA, Esterman A, et al. 15s: they fit Wilson DH, Wakefield MA, Esterman A, et al. 15s: they fit
in anywhere-especially the school bag: a survey of purchases of packets of 15 cigarettes by 14 and 15 year olds in South Australia. Commun Health Stud 1987; 11(suppl).

7 Eleven face court after death fires. South China Morning Post 1988 Jun 14:8.

8 Blum A. If smoking killed baby seals . . . New York State $\mathcal{F}$ Med 1985;85:282-5.

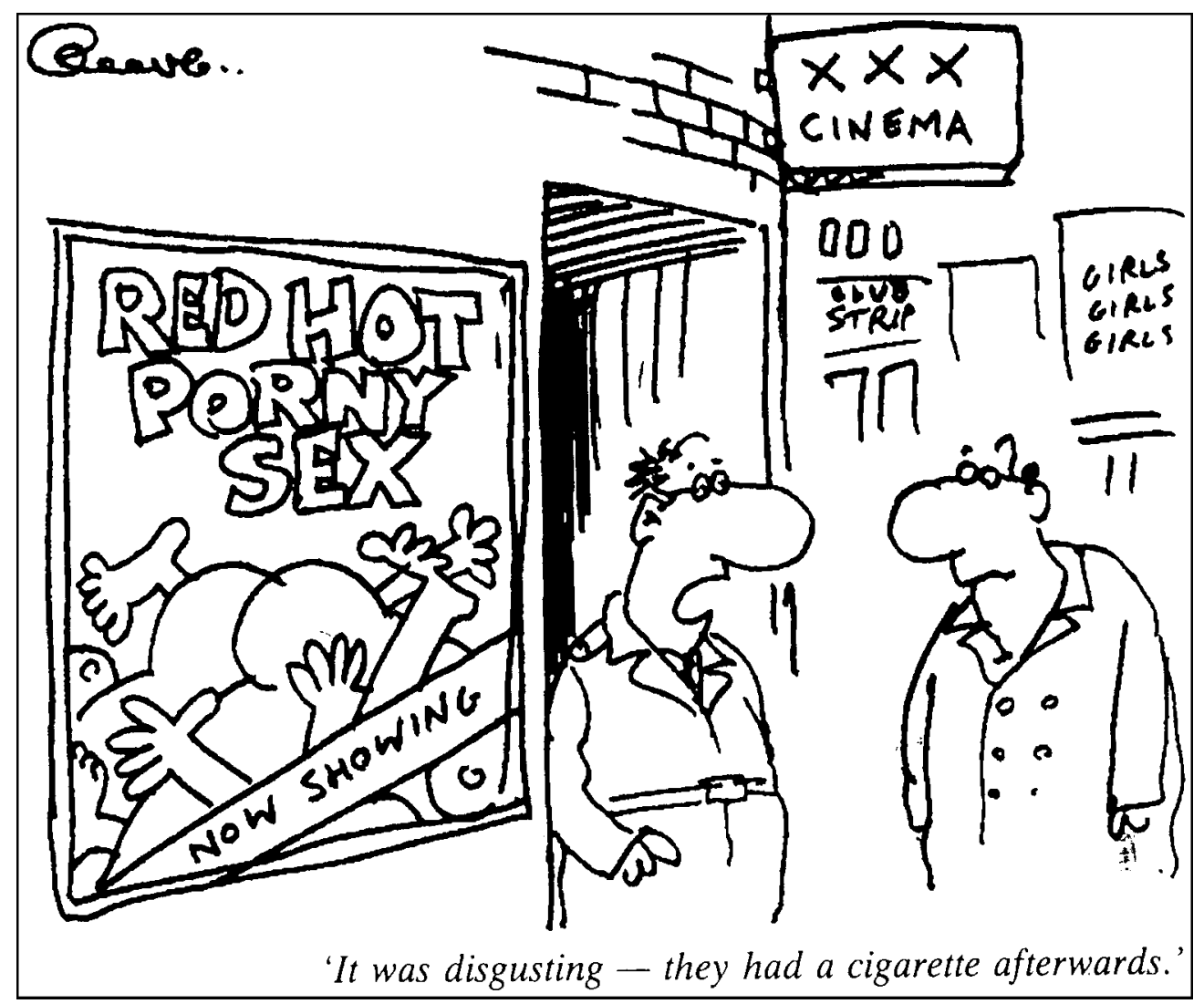

By Cleave, 1993. Reproduced courtesy of "The Spectator". 